\title{
Chemical Ecology of Egg Parasitoids Associated with True Bugs
}

\author{
Eric Conti ${ }^{1}$ and Stefano Colazza ${ }^{2}$ \\ ${ }^{1}$ Dipartimento di Scienze Agrarie e Ambientali, Università degli Studi di Perugia, Borgo XX Giugno, 06121 Perugia, Italy \\ ${ }^{2}$ Dipartimento DEMETRA, Università degli Studi di Palermo, Viale delle Scienze, Building 5, 90128 Palermo, Italy
}

Correspondence should be addressed to Eric Conti, econti@unipg.it

Received 17 December 2011; Accepted 3 March 2012

Academic Editor: Jeffrey R. Aldrich

Copyright ( 92012 E. Conti and S. Colazza. This is an open access article distributed under the Creative Commons Attribution License, which permits unrestricted use, distribution, and reproduction in any medium, provided the original work is properly cited.

Parasitoids representing some 15 families of Hymenoptera develop in insect eggs; three of these families, Platygastridae (= Scelionidae), Mymaridae, and Encyrtidae, are associated with Heteroptera. Several species of heteropteran egg parasitoids are or may be important for biological pest control. Successful parasitism of insect herbivores by insect parasitoids arises through several phases of host searching, which lead female wasps to the vicinity of, or in contact with, their hosts. During the host location process, females encounter and explore a variety of stimuli, among which chemical cues (i.e., semiochemicals or infochemicals) play a pivotal role. Female parasitoids are under selection pressure to efficiently invest their limited time on the location and exploitation of host-derived stimuli. In general, the levels of reliability and detectability of a particular stimulus are inversely correlated. Female parasitic wasps adopt differing strategies to solve this dilemma. In this paper we focus on the various host selection strategies employed by heteropteran egg parasitoids and possible means whereby the chemically mediated behavior of these wasps may be exploited to enhance biological pest control.

\section{Introduction}

Egg parasitoids are the largest group of entomophagous insects associated with Heteroptera. Thus, considering that they attack the host before it develops and inflict feeding damage, egg parasitoids show remarkable potential as biological control agents of Heteroptera, as well as other pests [1]. These parasitoids, however, also attack predaceous bugs which, of course, is counterproductive for the efficacy of these important natural enemies $[2,3]$.

Of the approximately 15 hymenopteran families that include egg parasitoids, those most commonly associated with Heteroptera are Platygastridae, Mymaridae, and Encyrtidae [1]. Most studies of their chemical ecology concern species associated with herbivorous bugs and, to a much lesser extent, predacious Heteroptera. The majority of semiochemical research on egg parasitoids associated with true bugs has been limited to species belonging to the genera attacking economically important pentatomid, scutellerid, mirid, alydid, and coreid plant pests (Table 1): Trissolcus, Telenomus, Gryon (Platygastridae = Scelionidae; see Sharkey [4] and Murphy et al., 2007 [5]), Anaphes (Mymaridae), and Ooencyrtus (Encyrtidae).
Generally, in order to reproduce, a female parasitoid must find its host at a stage suitable for parasitization. The host selection process involves a sequence of phases mediated by physical and chemical stimuli from the host, the substrate, and/or associated organisms, eventually leading to successful parasitism [6-9]. Because parasitoid foraging time is limited and the potential cues available are numerous, the parasitoid faces the need to optimize exploitation of available cues and discriminate those most reliable in indicating the presence of a suitable host $[8,10]$. However, the location and recognition of a suitable host is a complex process, especially for egg parasitoids, because of major constraints due to the small sizes of both the host and the parasitoid itself. Eggs are usually unapparent, especially when they are small, dispersed in the habitat, and concealed in plant tissue. As such, cues that are directly related to the presence of eggs may have low detectability, but high reliability $[8,11,12]$. Additionally, suitable host eggs are generally available for only a short time due to their rapid development [7]. Therefore, egg parasitoids have developed specialized strategies to overcome the reliability-detectability dilemma in order to efficiently parasitize host eggs. Successful parasitism is accomplished 


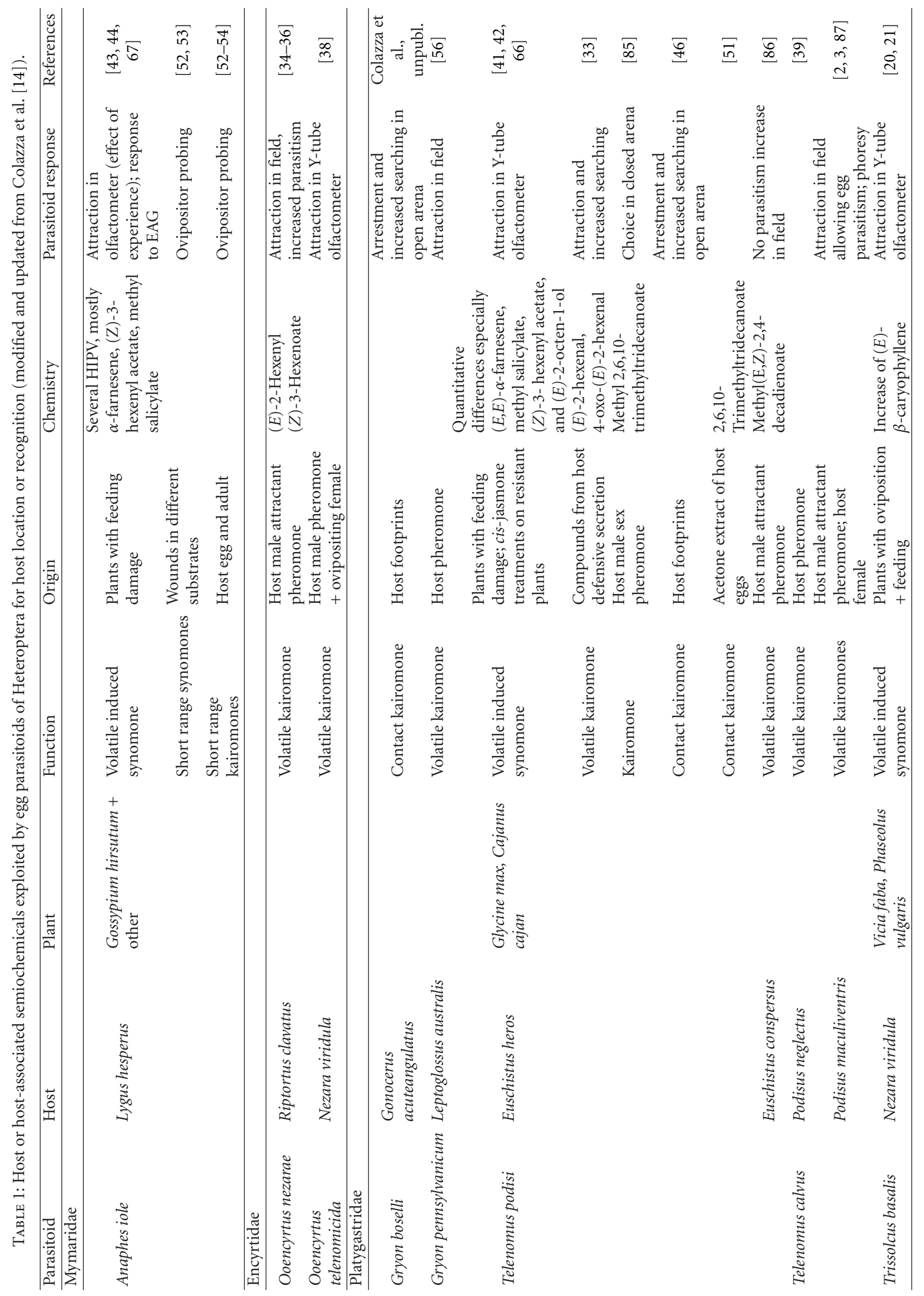




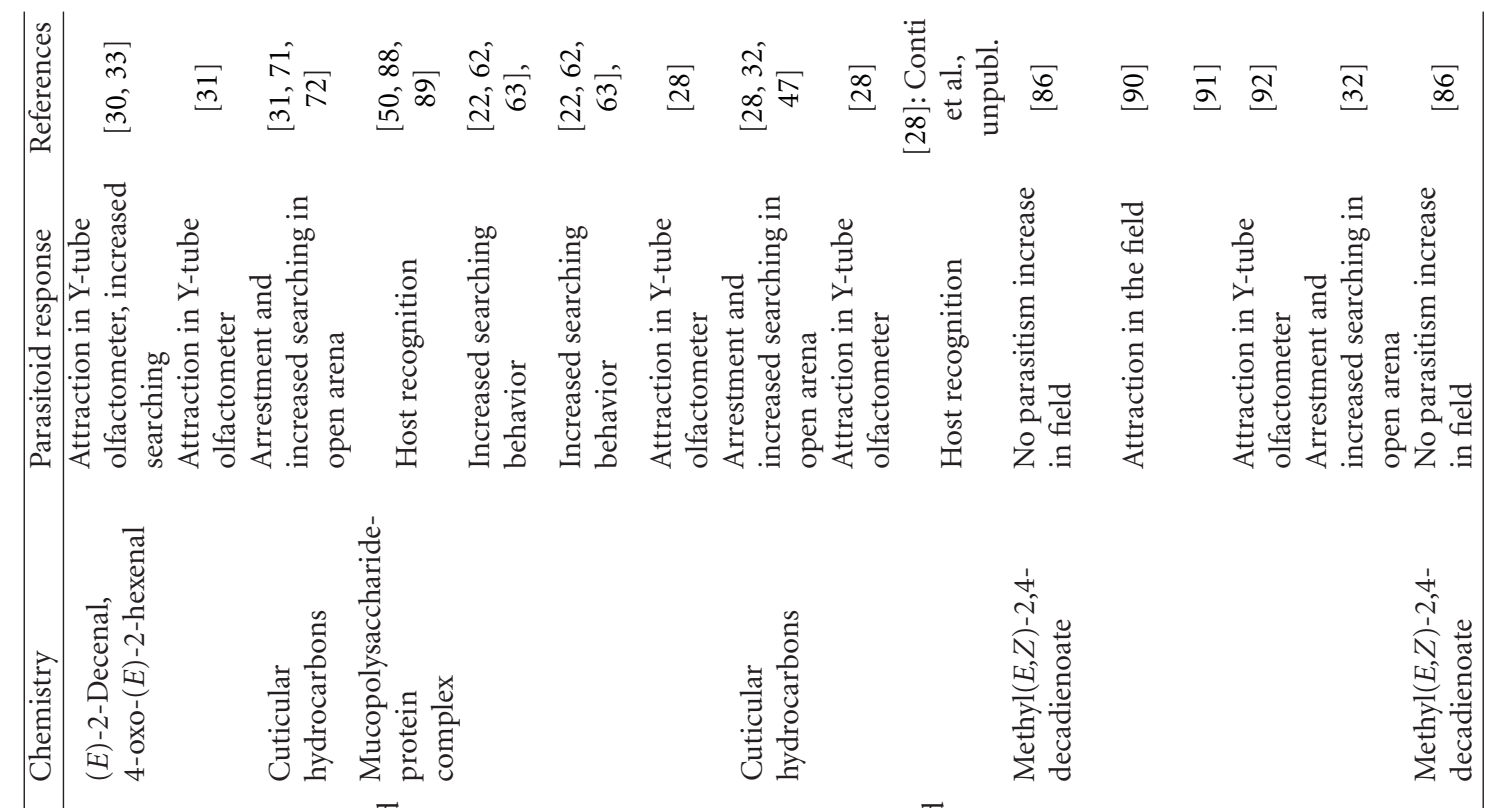

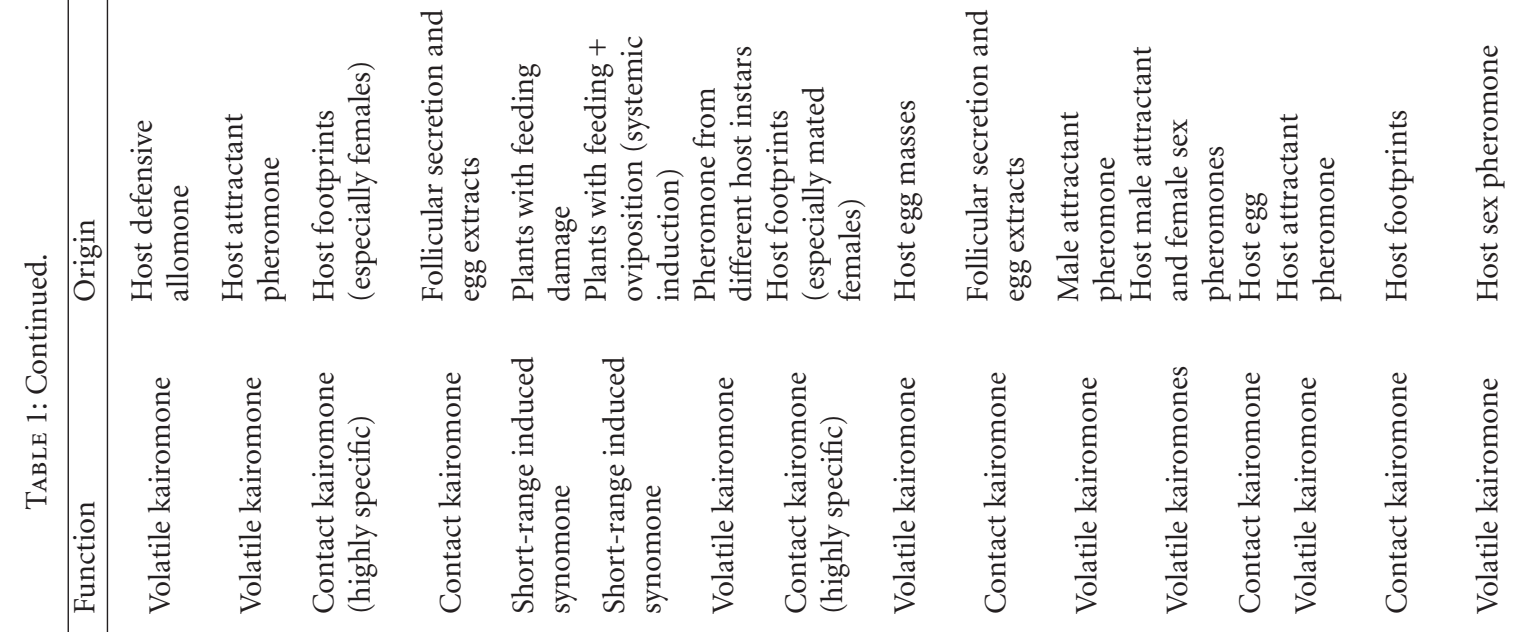<smiles>C1[C@H]2C[C@@H]12</smiles> 
through the combined exploitation of cues that are directly and indirectly related to host eggs [7, 8, 13, 14]. First, parasitoids may detect volatiles from nontarget instars of the host, that is, adults or juveniles, to reach the vicinity of the host eggs (infochemical detour sensu Vet \& Dicke [8]), eventually enabling them to pin-point eggs using additional long- and/or short-range cues. A particular and interesting example of such detour behavior of egg parasitoids is phoresy on adult host females; via this strategy, not only are relevant cues more detectable, but the adult itself is also exploited by the parasitoid as a vehicle to arrive at host eggs [15-17]. Second, parasitoids may exploit plant volatiles induced as a consequence of herbivory, which are emitted in large quantities and are, therefore, easily detectable by foraging parasitoids but not necessarily highly reliable [13]. For example, recent investigations have shown that some egg parasitoids are capable of exploiting plant chemicals emitted as a result of egg deposition, thus rendering such highly detectable cues also highly reliable [18-24]. Third, egg parasitoids have been observed to associate, through learning, highly detectable but less reliable cues with the presence of suitable hosts, thus increasing reliability of such cues in experienced wasp females $[25,26]$.

The complex of stimuli that are used by parasitoids for host seeking and acceptance, originating from the host, the associated substrate and/or organisms, and their possible interactions, has been called the "host-egg unit" [27-29]. The host-egg unit is often quite complex and is related to the parasitoid strategies described above. Thus, the same host might represent different host units for different parasitoids, depending on whether they are specialist versus generalist parasitoids, or whether they have evolved capabilities to exploit adult kairomones or induced plant synomones, or whether they have developed phoretic strategies. In this paper we will focus on the behavioral steps of host selection strategies and the chemical cues exploited by egg parasitoids of emerging pest species of Heteroptera.

\section{Exploitation of Indirect versus Direct Host-Related Chemical Cues}

The most common indirect host-finding tactic known thus far for egg parasitoids is the infochemical detour strategy based on the parasitoid ability to detect chemical cues associated with stages other than the egg $[7,8]$. Exploitation of pheromones and/or allomones from host adults has been demonstrated for both Platygastridae [28, 30-33] and Encyrtidae [34-38] (Table 1). These stimuli provide indirect information on the presence of the host community, leading the wasp female to the vicinity of host eggs. In spite of their low reliability, pheromones and allomones are produced in large amounts, and, therefore, these cues are relatively easy to detect by the female wasps from long to medium distances [39].

Phoresy is a different, but highly specialized bridgein-time (and bridge-in-space) strategy exploited by egg parasitoids to reduce the spatial and temporal discontinuity between where host adults mate and where host females oviposit [7, 40]. One well-documented case of phoresy by a heteropteran egg parasitoid is that of Telenomus calvus Johnson (Platygastridae) females that parasitize eggs of the predacious spined soldier bug, Podisus maculiventris (Say) (Pentatomidae). Female T. calvus wasps go to the maleproduced $P$. maculiventris attractant pheromone, wait nearby for a conspecific soldier bug female to arrive and mate, and then become phoretic on the mated host female until she eventually oviposits $[2,3]$.

Another indirect means to locate host eggs is exhibited by Trissolcus basalis (Woll.) and Telenomus podisi Ash. (Platygastridae), which exploit plant synomones induced by oviposition and/or feeding of their hosts, Nezara viridula L. [20] and Euschistus heros (Fabr.) [41, 42] (Pentatomidae) (Table 1). In a hierarchical context, whether volatiles from host adults or from the host plants of host adults are exploited from the furthest distance has yet to be elucidated. In the case of Tr. basalis, because host oviposition is necessary for volatile induction in bean plants, such synomones appear more reliable compared to kairomones from nontarget instars or to feeding-induced synomones [20, 21]. Therefore, it can be hypothesized that kairomones from adults and feeding-induced plant synomones act as a long-distance, indirect cue used to localize the host community (or host habitat), whereas oviposition-induced plant synomones are shorter-range cues used to find plants that actually have host eggs.

Induced plant volatiles are also exploited by mymarids $[43,44]$ (Table 1). Feeding on cotton, and several other plants, by either sex of Lygus hesperus Knight (Miridae) results in the induction of volatiles that are behaviorally and physiologically active towards Anaphes iole Girault (Mymaridae). Oviposition appears unnecessary to induce active volatiles [44]; therefore, these synomones should also be considered as indirect cues, exploited to localize the host community.

Once close to a potential host, female parasitic wasps in flight preferably should alight on a plant that probably has host eggs and then commence searching on the substrate for suitable eggs. Different strategies, and cues, are used during this phase (Table 1). For example, Trissolcus brochymenae (Ashm.) exploits short-range chemicals that are induced in cabbage plants by Murgantia histrionica (Hahn) (Pentatomidae) during oviposition [22]. Such a directly host-related synomone that is systemically emitted by the plant provides reliable information on the presence of suitable host eggs, but not necessarily precise information on where the eggs have been laid [22].

While searching for the host eggs on the plant, different Platygastridae were shown to use chemical traces left behind from the adults and/or juveniles (Table 1). The typical response to such cues, which are perceived through gustatory sensilla [45], is arrestment behavior followed by increased searching intensity $[28,31,32,46]$. These cues are not directly related to the host eggs, but because of finely tuned adaptations of the parasitoid, these cues may become quite reliable. In fact, although responding to the "footprints" of both males and females of the host species, Tr. basalis and Tr. brochymenae are able to discriminate host adult sex and 
the physiological conditions of host adults (e.g., virgin versus mated females) [28, 31, 47, 48]. Interestingly, in addition to chemical footprints, Te. podisi also uses vibratory signals mediating sexual behavior of the host species, E. heros [49].

Short-range host location is the next and final step, and female wasps may use visual cues at this point or shortdistance kairomones directly related to the host to finally reach the target egg. The presence of volatiles from $M$. histrionica eggs is detectable by Tr. brochymenae whereas, in this species, visual cues do not appear to play an important role [28] (Table 1). When a host egg mass is encountered, host recognition by Trissolcus species is elicited by contact kairomones present on the egg surface, although physical factors such as shape and size may also affect wasp behavior $[28,50,51]$ (Table 1). Short-range physical and chemical stimuli from the plant and host egg are also exploited by $A$. iole to locate and recognize $L$. hesperus eggs embedded in plant tissue [52-54].

\section{Long-Range Kairomones from Nontarget Instars of the Host}

As mentioned above, a well-known solution for the egg parasitoids to overcome the low detectability of host egg cues is to eavesdrop on the pheromonal communication (sex and other attractant pheromones), or the allomonal defenses, of nontarget stages of their hosts. This strategy was initially studied for egg parasitoids of Lepidoptera (reviewed by Fatouros et al. [13]; Colazza et al. [14]), but several cases are also known under laboratory and field conditions for species associated with Heteroptera (Table 1).

In early laboratory experiments using Y-tube olfactometers, Tr. basalis was found to be attracted by volatiles from adults of $N$. viridula [55]. A subsequent study revealed that (E)-2-decenal, a component of the defensive secretion from the metathoracic scent gland of N. viridula, is responsible for this dose-dependent attraction [30]. More recently, both Tr. basalis and Te. podisi were found to be attracted to and increase their searching behavior in the presence of defensive compounds from metathoracic scent gland secretions of their hosts, N. viridula and E. heros [33]. Trissolcus basalis showed a significant preference for $(E)$-2-decenal and 4oxo-(E)-2-hexenal, while Te. podisi responded positively to (E)-2-hexenal and 4-oxo-(E)-2-hexenal [33]. In addition to volatiles from metathoracic glands, those from the dorsal abdominal glands of nymphs also appear to be exploited as kairomones by Tr. basalis, but nymphal secretions may be attractive at intermediate range rather than long range [39].

Detailed investigations of Tr. basalis responses to volatiles from both sexes of $N$. viridula showed that the female egg parasitoid is attracted to the males and to preovipositional females, whereas it is not attracted to virgin females [31]. When males and preovipositional females were assayed in a two-choice test, the parasitoid preferred females [31]. Similar results were obtained in a Y-tube olfactometer with Tr. brochymenae, as this parasitoid was attracted by cues from differing stages (eggs, nymphs, and adults) and sexes but showed significant preference for gravid females when compared to males [28]. Therefore, volatile allomones and sex pheromones from host males can direct female wasps toward host aggregates, whereas volatiles from gravid females act hierarchically on a subsequent step, representing a more reliable indicator of the potential presence of host eggs [28, 31 .

The generalist egg parasitoid, Ooencyrtus telenomicida (Vassiliev) (Encyrtidae), is attracted in Y-tube olfactometer to odors of virgin male and, less intensely, of mated $N$. viridula females in preovipositional state, suggesting that the parasitoid exploits the host male-produced attractant pheromone [38]. When exposed to tomato plants treated with $N$. viridula or untreated control plants, O. telenomicida females did not respond to healthy or damaged plants, but only to plants with adult bugs, indicating that active volatiles originate from the host rather than the plant [38]. Field experiments confirm parasitoid attraction towards host adults. Traps baited with the synthetic attractant pheromone of male Riptortus clavatus (Thunberg) (Alydidae) captured females of the encyrtid egg parasitoid Ooencyrtus nezarae Ishii [34]. Males of $R$. clavatus emit an aggregation pheromone, composed of a blend of three compounds that attract adults of both sexes and nymphs. One compound, (E)-2-hexenyl (Z)-3-hexenoate, attracts females of $O$. nezarae and resulted in higher parasitism in treated fields compared with untreated fields [35, 36]. This tiny parasitoid has the remarkable ability to fly just above the plant canopy in nonhost habitat, while exploiting the above cues to reach the host habitat [37], although the exact flight mechanisms are unknown. In a different system, the use of traps baited with live adult Leptoglossus australis F. (Coreidae) resulted in increased parasitism efficacy by Gryon pennsylvanicum (Ashmead) (Platygastridae) [56].

Field confirmation of egg parasitoid response to the attractant pheromone of $P$. maculiventris [2] was also achieved [3]. The phoretic females of Te. calvus Johnson parasitized significantly more host eggs in pheromone-baited versus nonbaited traps, whereas the generalist Te. podisi did not show any significant differences. As described earlier, Te. calvus females exploit the male attractant pheromone of $P$. maculiventris to locate females during mating and then become phoretic on mated female bugs $[2,3]$.

\section{Plant Synomones Induced by Feeding or Oviposition}

Host-induced plant synomones are reliable and readily available cues for foraging parasitoids that attack feeding stages of hosts $[8,57,58]$. Egg parasitoids may respond to plant synomones induced by feeding [22, 41, 43]. However, not only feeding but also oviposition by herbivores induces emission of plant compounds acting as synomones between the primary and tertiary trophic levels towards their respective egg parasitoids [18-22, 59-65] (Table 1).

Each of the above systems has unique characteristics vis-à-vis induced plant defenses. Important differences are the cause of induction (i.e., oviposition, feeding, or a combination of the two, i.e., direct versus indirect cues), 
the type of oviposition (i.e., exposed or embedded), and the relationship between egg and plant (i.e., magnitude of synomone emission, local or systemic emission, and activity range of synomone). Other important differences involve timing of synomone release (often reliably related to host suitability), the elicitor source, and, if known, the chemistry of the induced synomone.

4.1. Egg Parasitoid Exploitation of Feeding-Induced Synomones. Feeding likely induces higher synomone levels than does egg deposition. Regardless, exploitation of such indirect host-related cues seems to have evolved because it allows parasitoids to minimize the searching area, thus maximizing efficiency.

Tritrophic plant/bug/egg parasitoid systems involving Heteroptera have been described for Glycine max and Cajanus cajan (Leguminosae)/E. heros/Te. Podisi/[41, 42, 66]; Brassica oleracea (Cruciferae)/M. histrionica/Tr. brochymenae (including oviposition-induced synomones) [22, 62, 63]; Gossypium hirsutum (Malvaceae) and other plants/L. hesperus/A. iole [43].

In olfactometer tests, Te. podisi responded to volatiles from soybean and pigeon pea fed upon by adults and nymphs of E. heros [41]. Application of cis-jasmone elicited a similar volatile profile from soybean plants after 96 hours with quantitative, rather than qualitative, chemical differences and resulted in the concomitant attraction of egg parasitoids [66]. Remarkably, when resistant versus susceptible soybean cultivars were compared, parasitoids were only attracted to resistant cultivars; volatile profiles in damaged plants differed between cultivars. In addition, volatiles from ovipositiondamaged plants did not attract Te. podisi females [42].

Trissolcus brochymenae females' response to plant volatiles induced by host feeding is different than that of Te. podisi females. What is known for the former parasitoid indicates that females mainly exploit plant compounds systemically induced by a combination of oviposition, feeding punctures, and footprints of its host, $M$. histrionica, to elicit host searching. Nevertheless, failure to actually oviposit by the host still induces emission of leaf-surface volatiles but, in such cases, parasitoid response was observed only on the damaged leaves [22]. These types of cues appear less reliable compared with oviposition-induced cues, and would act hierarchically at a lower level than other semiochemical cues.

Olfactometer research with Anaphes iole Girault (Mymaridae) demonstrated that this species of egg parasitoid also employs volatiles from cotton and other herbaceous plants infested by adults of its host, L. hesperus [43]. Eggs of Lygus spp. are embedded through an incision made with the ovipositor in plant tissue, with only the operculum exposed, and compounds from these wounds elicit parasitoid behavioral responses even if no eggs have been laid $[52,53]$. Both oviposition and feeding damage cause volatiles to be emitted from cotton plants although oviposition appears to induce release of constitutive terpenes from specific glands in cotton leaves adjacent to the oviposition incision, whereas feeding resulted in systemic induction of different volatiles
[67]. The volatile blend induced by L. hesperus salivary gland extracts is similar to that induced by volicitin, an elicitor isolated from the regurgitant of moth larvae [68], although chemical analyses of the salivary glands from Lygus spp. have shown no evidence of a volicitin-type of fatty acid-amino acid conjugate [67]. In electroantennogram (EAG) assays, $A$. iole responded to the majority of herbivore-induced plant volatiles tested, but most intensely to $(Z)$-3-hexenyl acetate, and methyl salicylate; females responded more than males [44]. Olfactometer and wind tunnel bioassays showed that the female wasps were positively stimulated by (Z)-3-hexenyl acetate, methyl salicylate and $\alpha$-farnesene, although response to ( $Z$ )-3-hexenyl acetate was exhibited only after preconditioning females to blends of host-plant odors. In field trials, host eggs baited with $\alpha$-farnesene and (Z)-3-hexenyl acetate were more heavily parasitized than were untreated eggs [44].

\subsection{Egg Parasitoid Exploitation of Oviposition-Induced} Synomones. Oviposition-induced synomones, which are directly related to the target stage, are highly reliable and detectable for egg parasitoids. Herbivore oviposition induces emission of plant compounds that act as synomones towards a variety of egg parasitoids [18-22, 59-65]. This "early herbivore alert" [69] by the plant denotes a particular type of indirect induced defense, which, among parasitoids of Heteroptera, has been observed in two tritrophic systems: Vicia faba and Phaseolus vulgaris (Leguminosae)/N. viridula/Tr. basalis [20, 21] and, Brassica oleracea (Cruciferae)/M. histrionica/Tr. brochymenae [22, 62, 63] (Table 1).

In the Heteroptera, the first case of plant volatile induction by a bug gluing eggs on leaves without causing mechanical damage is that of Nezara viridula ovipositing on legumes [20]. Trissolcus basalis was attracted by oviposition-induced volatiles in an olfactometer, and the volatile emission was systemic (i.e., from damaged and adjacent undamaged leaves) [20]. By maximizing the release surface, the plant may have evolved to increase synomone volatilization, thereby increasing herbivores apparency to egg parasitoids. Over time, synomone activity seems to be finely tuned to parasitoid behavior and biology since the attraction fades when host eggs are near to eclosion. Oviposition by $N$. viridula females on Vicia faba L. and Phaseolus vulgaris L., combined with feeding punctures, induced release of $(E)-\beta$ caryophyllene, as well as two other sesquiterpenes. Only the fraction containing (E)- $\beta$-caryophyllene attracted Tr. basalis [21]. Whether the elicitor originates from the eggs, follicular tissue, or elsewhere is unknown; however, the combined presence of feeding punctures is necessary for synomone induction [21].

The other known case of an oviposition-induced synomone for an egg parasitoid of true bugs is quite different from the one just described because the induced compounds act at a very short distance. Tr. brochymenae perceives the induced synomone only when it alights on a damaged plant $[22,62]$. Compared to healthy plants, females of this parasitoid intensely antennated and searched on leaves having a host egg mass, plus nearby feeding punctures and 
chemical footprints (treated surface). Parasitoid response was tested on the upper (adaxial) leaf surface, opposite to the treated (abaxial) surface. Female wasps also responded in a static olfactometer at near contact range to volatiles perceived through olfaction, but host-damaged plants in a Y-tube olfactometer were not attractive to wasps. As with $N$. viridula on leguminous plants, the induction is both local and systemic, but the origin of the elicitor and the mechanisms involved remain unknown. However, in the case of M. histrionica on cabbage, egg mass deposition is sufficient, as are feeding punctures, to elicit parasitoid response, although the combination of oviposition, feeding, and footprints increases parasitoid response [22]. Parasitoid reaction to compounds emitted as a consequence of host feeding appears to be a response to damaged host plants [22]; leaves with feeding punctures exhibit alteration of tissues and photosynthesis [70].

\section{Short-Range Kairomones from Nontarget Host Stages}

Indirect host-related cues originate from adults or juveniles of the host and, in general, elicit arrestment and searching behavior in the parasitoid. Trichogrammatidae and Platygastridae species responses to lepidopteran moth scales were studied earlier (reviewed by Colazza et al. [14]). However, a comparable strategy was also discovered for the heteropteran egg parasitoids, Trissolcus spp. [28, 31, 32, 71] Te. podisi [46], and Gryon boselli Mineo \& Szabo (Colazza, Lo Bue, and Cusimano, personal observation), which respond to chemical footprints of pentatomid bugs (Table 1). Both Tr. basalis and Tr. brochymenae females are able to discriminate chemical footprints left by host females, to which they respond more strongly than to chemical traces left by walking males or nymphs $[28,31,47,72]$. In addition, Tr. brochymenae is able to detect cues from mated females in the preovipositional state, which are preferred to virgin females and parous females (i.e., those that have already produced offspring), thus finely tuning their searching to the host stage most likely to lead to host eggs [47]. This preference was strictly related to the transfer of sperm and associated substances from the conspecific male bug to the female during copulation. The compounds mediating arrestment of Tr. brochymenae females are from host cuticle, and those that play a role as gender-specific cues are most abundant on the legs of the host adult [47].

Associative learning plays an important role in host footprint recognition behavior. Oviposition experience increased the arrestment response of Tr. basalis females to footprints of $N$. viridula females, whereas prior experience not followed by oviposition led to the gradual fading of the learned behavior [25]. In contrast, previous experience with the footprints of host males did not result in a change of parasitoid response, indicating that residues from males only provide general information for the parasitoid, which is not directly associated with host eggs [25]. There is significant variation in the learning ability of Tr. basalis females as a function of environment and spatial distribution, but learning always helps make foraging more successful [26].

Footprint chemistry was investigated in the Tr. BasalisN. viridula relationship. Analysis of extracts of cuticular lipids from $N$. viridula revealed the presence of normal alkanes, with quantitative and qualitative differences between the sexes. One compound, n-nonadecane, was recovered only from the cuticle and footprints of males. When added to cuticular extracts of $N$. viridula females, $n$-nonadecane caused Tr. basalis females to significantly reduce their residence time in the arena, similar to the behavior of female wasps in the presence of hexane extracts of male hosts [72]. Parasitoid response to host footprints is mediated by adsorption of the contact kairomone in the epicuticular wax layer of plants walked upon by host bugs $[48,73]$.

\section{Short-Range and Contact Kairomones from Host Eggs}

Semiochemicals from or on host eggs are likely present in faint amounts and, thus, are probably exploited by egg parasitoids only at close range or upon contact. Shortrange and contact kairomones are best known for egg parasitoids of Lepidoptera [14]. Among the Heteroptera, this semiochemical level has been investigated for the egg parasitoid of the harlequin bug (M. histrionica), $T$. brochymenae, in both a Y-tube olfactometer and an open arena. In the olfactometer the T. brochymenae females were attracted to volatiles from host egg masses, whereas, in the open arena, the female parasitoids oriented towards egg clusters or dummies treated with chemical extract of host eggs. When the egg extract was applied without dummies, it elicited the same response, whereas dummies without extract did not influence parasitoid behavior, indicating that visual factors are unnecessary for this last step in host location [28] (Table 1).

Parasitoid host recognition to egg contact kairomones is much more obvious than are responses to egg volatiles (Table 1). When in contact with the heteropteran host egg mass, Trissolcus spp. use both physical and chemical cues; egg size and the shape are important cues, but chemicals on the egg surface are fundamental for host acceptance [50]. The recognition kairomones are contained in the adhesive secretion from the follicular cells of heteropteran hosts [28, 50,51], composed of mucopolysaccharide-protein conjugants [50], but their chemical nature has not been defined yet. Surprisingly, (E)-2-decenal, a component of the defensive secretion from the metathoracic scent gland of $N$. viridula that was attractive to Tr. basalis in an olfactometer, also elicited parasitoid antennation and ovipositor probing of egg-sized glass beads [30].

When host eggs are embedded in plant tissue, semiochemicals may originate from the egg, the damaged plant, or from their interaction. Females of the mymarid, Anaphes iole, respond to Lygus eggs inserted into plant tissue with arrestment, increased antennation, and ovipositor probing even if oviposition wounds do not contain eggs, although probing is much more intense if the incision contains a host 
egg. Artificial wounds are also probed by the parasitoid, and so are eggs removed from the substrate and placed on a surface $[52,53]$. Although chemical cues appear to play a major role, physical cues are also important in this phase; $A$. iole females adopt a probing posture when chemicals from host or plants are combined with appropriate shapes [5254]. Electroantennogram assays showed that the parasitoid antennae sense several plant volatiles, including green leaf volatiles, confirming the importance of plant chemicals during host searching in this species [44]. Ovipositor probing behavior is the final step of host searching by $A$. iole, rather than merely host recognition; perhaps this explains why these mymarid females insert their ovipositor, although less frequently, even in artificial wounds made in a parafilm substrate containing neither host eggs nor contaminated by host material [52]. Moreover, learning host and plant cues increases $A$. iole oviposition efficiency [53]; indeed, a preference for ( $Z$ )-3-hexenyl acetate occurs only after preconditioning with host-induced plant volatiles [44].

\section{Conclusions}

The importance of egg parasitoids as biological control agents for herbivorous insect pests is widely recognized. Nevertheless, their success in classical biological control programs is slightly lower than that for other kinds of introduced parasitoid species [74]. Several Mymaridae and Platygastridae species have been used for augmentative biological control of Heteroptera [74], the most successful of which involved releases of Tr. basalis against $N$. viridula on soybean in Brazil $[75,76]$.

While several egg parasitoids of Heteroptera are potentially effective biological control agents, there are still constraints preventing the realization of this goal. Incomplete behavioral and ecological knowledge for most parasitoid species remains problematic and, perhaps most importantly, mass production of egg parasitoids remains inefficient [7779]. Understanding the host selection strategies of egg parasitoids and the chemical stimuli involved could lead to improved biological control efficacy through behavioral manipulation of egg parasitoids in the field and to development of better in vivo and in vitro rearing methods. An estimated 16 million ha of cropland worldwide currently receives inundative releases of egg parasitoids, primarily involving species in the genus Trichogramma [77]. Efficient mass rearing of Trichogramma spp., as well as intensive, focused research preceded this achievement, including elucidation of the chemicals necessary for acceptance of artificial host media and the parasitoid development [79]. The success of Trichogramma biocontrol programs is a model of what may be achieved with other parasitoids given the required research investment.

Successful implementation of egg parasitoids against true bugs will depend on judicious applications of synthetic semiochemicals, particularly synomones and kairomones, and appropriate strategies to overcome existing constraints, including treatments facilitating parasitoid rearing, conditioning, and manipulation $[61,74,80,81]$. Other interesting possibilities include the development of plants with elevated expression of indirect induced resistance factors (i.e., the induction of plant synomones exploited by the herbivores' parasitoids) or spraying fields with resistance elicitors [61]. Accurate knowledge of parasitoid chemical ecology will be important in all phases of biocontrol and integrated pest management [82]; important elements toward implementation include procedures for selection of egg parasitoids, evaluation of their specificity $[27,32,71]$, risk assessment of new introductions [83], release methods [80], and quality control $[80,84]$. Implementation of knowledge gleaned from laboratory studies must finally be scaled up and transferred to growers.

\section{Acknowledgments}

The authors thank Ezio Peri for valuable comments and suggestions on this paper and Jeff Aldrich for accurate revision that improved the final paper. Funding for this project was provided by MIUR-PRIN 2009.

\section{References}

[1] F. Bin, "Biological control with egg parasitoids other than Trichogramma," in Biological Control with Egg Parasitoids, E. Wajnberg and S. A. Hassan, Eds., pp. 245-271, CAB International, Oxford, UK, 1994.

[2] J. R. Aldrich, J. P. Kochansky, and C. B Abrams, "Attractant for a beneficial insect and its parasitoids: pheromone of a predatory spined soldier bug, Podisus maculiventris (Hemiptera: Pentatomidae)," Environmental Entomology, vol. 13, pp. 10311036, 1984.

[3] R. Bruni, J. Sant'Ana, J. R. Aldrich, and F. Bin, "Influence of host pheromone on egg parasitism by scelionid wasps: comparison of phoretic and nonphoretic parasitoids," Journal of Insect Behavior, vol. 13, no. 2, pp. 165-173, 2000.

[4] M. J. Sharkey, "Phylogeny and classification of hymenoptera," Zootaxa, no. 1668, pp. 521-548, 2007.

[5] N. P. Murphy, D. Carey, L. R. Castro, M. Dowton, and A. D. Austin, "Phylogeny of the platygastroid wasps (Hymenoptera) based on sequences from the 18S rRNA, 28S rRNA and cytochrome oxidase I genes: implications for the evolution of the ovipositor system and host relationships," Biological Journal of the Linnean Society, vol. 91, no. 4, pp. 653-669, 2007.

[6] S. B. Vinson, "The behaviour of parasitoids," in Comprehensive Insect Physiology Biochemistry and Pharmacology, G. A. Kerkut and L. I. Gilbert, Eds., pp. 417-469, Pergamon Press, New York, NY, USA, 1985.

[7] S. B. Vinson, "The general host selection behavior of parasitoid hymenoptera and a comparison of initial strategies utilized by larvaphagous and oophagous species," Biological Control, vol. 11, no. 2, pp. 79-96, 1998.

[8] L. E. M. Vet and M. Dicke, "Ecology of infochemical use by natural enemies in a tritrophic context," Annual Review of Entomology, vol. 37, no. 1, pp. 141-172, 1992.

[9] H. C. J. Godfray, Parasitoids. Behavioral and Evolutionary Ecology, Princeton University Press, Princeton, NJ, USA, 1994.

[10] M. Hilker and J. McNeil, "Chemical and behavioral ecology in insect parasitoids: how to behave optimally in a complex odorous environment," in Behavioral Ecology of Insect Parasitoids, 
E. Wajnberg, C. Bernstein, and J. van Alphen, Eds., pp. 693 705, Blackwell Publishing, 2007.

[11] S. B. Vinson, "Physiological interactions between egg parasitoids and their hosts," in Biological control with egg parasitoids, E. Wajnberg and S. A. Hassan, Eds., pp. 245-271, CAB International, Oxford, UK, 1994.

[12] L. E. M. Vet, W. J. Lewis, and R. Cardè, "Parasitoid foraging and learning," in Chemical Ecology of Insects, R. Cardè and W. J. Bell, Eds., pp. 65-101, Chapman \& Hall, New York, NY, USA, 1995.

[13] N. E. Fatouros, M. Dicke, R. Mumm, T. Meiners, and M. Hilker, "Foraging behavior of egg parasitoids exploiting chemical information," Behavioral Ecology, vol. 19, no. 3, pp. 677-689, 2008.

[14] S. Colazza, E. Peri, G. Salerno, and E. Conti, "Host searching by egg parasitoids: exploitation of host chemical cues," in Egg Parasitoids in Agroecosystems with Emphasis on Trichogramma, F. L. Cônsoli, J. R. P. Parra, and R. A. Zucchi, Eds., pp. 97-147, Springer, London, UK, 2010.

[15] C. P. Clausen, "Phoresy among entomophagous insects," Annual Review of Entomology, vol. 21, pp. 343-368, 1976.

[16] M. E. Huigens, F. G. Pashalidou, M. H. Qian et al., "Hitchhiking parasitic wasp learns to exploit butterfly antiaphrodisiac," Proceedings of the National Academy of Sciences of the United States of America, vol. 106, no. 3, pp. 820-825, 2009.

[17] M. E. Huigens, J. B. Woelke, F. G. Pashalidou, T. Bukovinszky, H. M. Smid, and N. E. Fatouros, "Chemical espionage on species-specific butterfly anti-aphrodisiacs by hitchhiking Trichogramma wasps," Behavioral Ecology, vol. 21, no. 3, pp. 470-478, 2010.

[18] T. Meiners and M. Hilker, "Host location in Oomyzus gallerucae (hymenoptera: eulophidae), an egg parasitoid of the elm leaf beetle Xanthogaleruca luteola (coleoptera: chrysomelidae)," Oecologia, vol. 112, no. 1, pp. 87-93, 1997.

[19] T. Meiners and M. Hilker, "Induction of plant synomones by oviposition of a phytophagous insect," Journal of Chemical Ecology, vol. 26, no. 1, pp. 221-232, 2000.

[20] S. Colazza, A. Fucarino, E. Peri, G. Salerno, E. Conti, and F. Bin, "Insect oviposition induces volatile emission in herbaceous plants that attracts egg parasitoids," Journal of Experimental Biology, vol. 207, no. 1, pp. 47-53, 2004.

[21] S. Colazza, J. S. McElfresh, and J. G. Millar, "Identification of volatile synomones, induced by Nezara viridula feeding and oviposition on bean spp., that attract the egg parasitoid: Trissolcus basalis," Journal of Chemical Ecology, vol. 30, no. 5, pp. 945-964, 2004.

[22] E. Conti, G. Salerno, B. Leombruni, F. Frati, and F. Bin, "Shortrange allelochemicals from a plant-herbivore association: a singular case of oviposition-induced synomone for an egg parasitoid," Journal of Experimental Biology, vol. 213, no. 22, pp. 3911-3919, 2010.

[23] M. Hilker and T. Meiners, "How do plants "notice" attack by herbivorous arthropods?" Biological Reviews, vol. 85, no. 2, pp. 267-280, 2010.

[24] M. Hilker and T. Meiners, "Plants and insect eggs: how do they affect each other?" Phytochemistry, vol. 72, no. 13, pp. 16121623, 2011.

[25] E. Peri, M. A. Sole, E. Wajnberg, and S. Colazza, "Effect of host kairomones and oviposition experience on the arrestment behavior of an egg parasitoid," Journal of Experimental Biology, vol. 209, no. 18, pp. 3629-3635, 2006.

[26] G. Dauphin, P. Coquillard, S. Colazza, E. Peri, and É. Wajnberg, "Host kairomone learning and foraging success in an egg parasitoid: a simulation model," Ecological Entomology, vol. 34, no. 2, pp. 193-203, 2009.

[27] E. Conti, F. Bin, and S. B. Vinson, "Host range in egg parasitoids: a tentative approach through the analysis of the host unit," in Proceedings of the 7th European Workshop on Insect Parasitoids, p. 32, Haarlem, The Netherlands, 2000.

[28] E. Conti, G. Salerno, F. Bin, H. J. Williams, and S. B. Vinson, "Chemical cues from Murgantia histrionic eliciting host location and recognition in the egg parasitoid Trissolcus brochymenae," Journal of Chemical Ecology, vol. 29, no. 1, pp. 115-130, 2003.

[29] S. B. Vinson, "Nutritional ecology of insect egg parasitoids," in Egg parasitoids in agroecosystems with emphasis on Trichogramma, F. L. Cônsoli, J. R. P. Parra, and R. A. Zucchi, Eds., pp. 25-55, Springer, London, UK, 2010.

[30] L. Mattiacci, S. B. Vinson, H. J. Williams, J. R. Aldrich, and F. Bin, "A long-range attractant kairomone for egg parasitoid Trissolcus basalis, isolated from defensive secretion of its host, Nezara viridula," Journal of Chemical Ecology, vol. 19, no. 6, pp. 1167-1181, 1993.

[31] S. Colazza, G. Salerno, and E. Wajnberg, "Volatile and contact chemicals released by Nezara viridula (heteroptera:pentatomidae) have a kairomonal effect on the egg parasitoid Trissolcus basalis (Hymenoptera: Scelionidae)," Biological Control, vol. 16, no. 3, pp. 310-317, 1999.

[32] E. Conti, G. Salerno, F. Bin, and S. B. Vinson, "The role of host semiochemicals in parasitoid specificity: a case study with Trissolcus brochymenae and trissolcus simoni on pentatomid bugs," Biological Control, vol. 29, no. 3, pp. 435-444, 2004.

[33] R. A. Laumann, M. F. S. Aquino, M. C. B. Moraes, M. Pareja, and M. Borges, "Response of the egg parasitoids Trissolcus basalis and Telenomus podisi to compounds from defensive secretions of stink bugs," Journal of Chemical Ecology, vol. 35, no. 1, pp. 8-19, 2009.

[34] W. S. Leal, H. Higuchi, N. Mizutani, H. Nakamori, T. Kadosawa, and M. Ono, "Multifunctional communication in Riptortus clavatus (heteroptera: alydidae): conspecific nymphs and egg parasitoid Ooencyrtus nezarae use the same adult attractant pheromone as chemical cue," Journal of Chemical Ecology, vol. 21, no. 7, pp. 973-985, 1995.

[35] N. Mizutani, T. Wada, H. Higuchi, M. Ono, and W.S. Leal, "A component of a synthetic aggregation pheromone of Riptortus clavatus (Thunberg) (Heteroptera: Alydidae), that attracts an egg parasitoid, Ooencyrtus nezarae Ishii (Hymenoptera: Encyrtidae)," Applied Entomology and Zoology, vol. 32, pp. 504-507, 1997.

[36] N. Mizutani, "Pheromones of male stink bugs and their attractiveness to their parasitoids," Japanese Journal of Applied Entomology and Zoology, vol. 50, no. 2, pp. 87-99, 2006.

[37] K. Takasu, S. I. Takano, N. Mizutani, and T. Wada, "Flight orientation behavior of Ooencyrtus nezarae (Hymenoptera: Encyrtidae), an egg parasitoid of phytophagous bugs in soybean," Entomological Science, vol. 7, pp. 201-206, 2004.

[38] E. Peri, A. Cusumano, A. Agrò, and S. Colazza, "Behavioral response of the egg parasitoid Ooencyrtus telenomicida to hostrelated chemical cues in a tritrophic perspective," Biocontrol, vol. 56, no. 2, pp. 163-171, 2011.

[39] J. R. Aldrich, "Chemical communication in true bugs and exploitation by parasitoids and commensals," in Chemical Ecology of Insects II, R. T. Carde and W. J. Bell, Eds., pp. 318363, Chapman \& Hall, London, UK, 1995.

[40] N. E. Fatouros and M. E. Huigens, "Phoresy in thefield: natural occurrence of Trichogramma egg parasitoids on butterflies and moths," BioControl. In press. 
[41] M. C. B. Moraes, R. Laumann, E. R. Sujii, C. Pires, and M. Borges, "Induced volatiles in soybean and pigeon pea plants artificially infested with the neotropical brown stink bug, Euschistus heros, and their effect on the egg parasitoid, Telenomus podisi," Entomologia Experimentalis Et Applicata, vol. 115, no. 1, pp. 227-237, 2005.

[42] M. F. F. Michereff, R. A. Laumann, M. Borges et al., "Volatiles mediating a plant-herbivore-natural enemy interaction in resistant and susceptible soybean cultivars," Journal of Chemical Ecology, vol. 37, no. 3, pp. 273-285, 2011.

[43] V. Manrique, W. A. Jones, L. H. Williams, and J. S. Bernal, "Olfactory responses of Anaphes iole (Hymenoptera: Mymaridae) to volatile signals derived from host habitats," Journal of Insect Behavior, vol. 18, no. 1, pp. 89-104, 2005.

[44] L. Williams, C. Rodriguez-Saona, S. C. Castle, and S. Zhu, "Eag-active herbivore-induced plant volatiles modify behavioral responses and host attack by an egg parasitoid," Journal of Chemical Ecology, vol. 34, no. 9, pp. 1190-1201, 2008.

[45] R. Romani, N. Isidoro, and F. Bin, "Antennal structure use in communication by egg parasitoids," in Egg Parasitoids in Agroecosystems with Emphasis on Trichogramma, F. L. Cônsoli, J. R. P. Parra, and R. A. Zucchi, Eds., pp. 57-96, Springer, London, UK, 2010.

[46] M. Borges, S. Colazza, P. Ramirez-Lucas, K. R. Chauhan, M. C. Blassioli Moraes, and J. R. Aldrich, "Kairomonal effect of walking traces from Euschistus heros (Heteroptera: Pentatomidae) on two strains of Telenomus podisi (Hymenoptera: Scelionidae)," Physiological Entomology, vol. 28, no. 4, pp. 349355, 2003.

[47] G. Salerno, F. Frati, E. Conti, C. De Pasquale, E. Peri, and S. Colazza, "A finely tuned strategy adopted by an egg parasitoid to exploit chemical traces from host adults," Journal of Experimental Biology, vol. 212, no. 12, pp. 1825-1831, 2009.

[48] D. Lo Giudice, M. Riedel, M. Rostás, E. Peri, and S. Colazza, "Host sex discrimination by an egg parasitoid on brassica leaves," Journal of Chemical Ecology, vol. 37, no. 6, pp. 622$628,2011$.

[49] R. A. Laumann, M. C. B. Moraes, A. Čokl, and M. Borges, "Eavesdropping on sexual vibratory signals of stink bugs (Hemiptera: Pentatomidae) by the egg parasitoid Telenomus podisi," Animal Behaviour, vol. 73, no. 4, pp. 637-649, 2007.

[50] F. Bin, S. B. Vinson, M. R. Strand, S. Colazza, and W. A. Jones, "Source of an egg kairomone for Trissolcus basalis, a parasitoid of Nezara viridula," Physiological Entomology, vol. 18, pp. 7-15, 1993.

[51] M. Borges, M. L. M. Costa, E. R. Sujii et al., "Semiochemical and physical stimuli involved in host recognition by Telenomus podisi (Hymenoptera: Scelionidae) toward Euschistus heros (heteroptera: pentatomidae)," Physiological Entomology, vol. 24, no. 3, pp. 227-233, 1999.

[52] E. Conti, W. A. Jones, F. Bin, and S. B. Vinson, "Physical and chemical factors involved in host recognition behavior of Anaphes iole girault, an egg parasitoid of lygus hesperus knight (Hymenoptera: Mymaridae; Heteroptera: Miridae)," Biological Control, vol. 7, no. 1, pp. 10-16, 1996.

[53] E. Conti, W. A. Jones, F. Bin, and S. B. Vinson, "Oviposition behavior of Anaphes iole, an egg parasitoid of lygus hesperus (Hymenoptera: Mymaridae; Heteroptera: Miridae)," Annals of the Entomological Society of America, vol. 90, no. 1, pp. 91-101, 1997.

[54] K. Takasu and D. A. Nordlund, "Host recognition kairomones for Anaphes iole girault, an egg parasitoid of the western tarnished plant bug," Biological Control, vol. 22, no. 1, pp. 6065, 2001.
[55] F. Bin, S. B. Vinson, and S. Colazza, "Responsiveness of Trissolcus basalis (Woll.) female (Hym.: Scelionidae) to Nezara viridula (L.) (Het.: Pentatomidae) in an olfactometer," Colloques de l'INRA, vol. 48, pp. 15-16, 1988.

[56] K. Yasuda and M. Tsurumachi, "Influence of male adults of the leaf-footed plant bug, Leptoglossus australis (Fabricius) (Heteroptera: Coreidae), on host-searching of the egg parasitoid, Gryon pennsylvanicum (Ashmead) (Hymenoptera: Scelionidae)," Applied Entomology and Zoology, vol. 30, no. 1, pp. 139-144, 1995.

[57] T. C. J. Turlings, J. H. Tumlinson, and W. J. Lewis, "Exploitation of herbivore-induced plant odors by host-seeking parasitic wasps," Science, vol. 250, no. 4985, pp. 1251-1253, 1990.

[58] M. G. Woldemariam, I. T. Baldwin, and I. Galis, "Transcriptional regulation of plant inducible defenses against herbivores: a mini-review," Journal of Plant Interactions, vol. 6, no. 2-3, pp. 113-119, 2011.

[59] M. Hilker, C. Kobs, M. Varama, and K. Schrank, "Insect egg deposition induces Pinus sylvestris to attract egg parasitoids," Journal of Experimental Biology, vol. 205, no. 4, pp. 455-461, 2002.

[60] M. Hilker, C. Stein, R. Schröder, M. Varama, and R. Mumm, "Insect egg deposition induces defence responses in Pinus sylvestris: characterisation of the elicitor," Journal of Experimental Biology, vol. 208, no. 10, pp. 1849-1854, 2005.

[61] M. Dicke and M. Hilker, "Induced plant defences: from molecular biology to evolutionary ecology," Basic and Applied Ecology, vol. 4, no. 1, pp. 3-14, 2003.

[62] E. Conti, G. Salerno, F. DeSantis, B. Leombruni, and F. Bin, "Difese indirette delle piante: i sinomoni per contatto indotti da ovideposizione," Atti Accademia Nazionale Italiana Entomologia, vol. 54, pp. 129-148, 2006.

[63] E. Conti, C. Zadra, G. Salerno et al., "Changes in the volatile profile of Brassica oleracea due to feeding and oviposition by Murgantia histrionic (Heteroptera: Pentatomidae)," European Journal of Entomology, vol. 105, no. 5, pp. 839-847, 2008.

[64] N. E. Fatouros, G. Bukovinszkine'Kiss, L. A. Kalkers, R. S. Gamborena, M. Dicke, and M. Hilker, "Oviposition-induced plant cues: do they arrest Trichogramma wasps during host location?" Entomologia Experimentalis Et Applicata, vol. 115, no. 1, pp. 207-215, 2005.

[65] N. E. Fatouros, G. Bukovinszkine'Kiss, M. Dicke, and M. Hilker, "The response specificity of Trichogramma egg parasitoids towards infochemicals during host location," Journal of Insect Behavior, vol. 20, no. 1, pp. 53-65, 2007.

[66] M. C. B. Moraes, R. A. Laumann, M. Pareja et al., "Attraction of the stink bug egg parasitoid Telenomus podisi to defence signals from soybean activated by treatment with cis-jasmone," Entomologia Experimentalis Et Applicata, vol. 131, no. 2, pp. 178-188, 2009.

[67] C. Rodriguez-Saona, S. J. Crafts-Brandner, L. Williams, and P. W. Paré, "Lygus hesperus feeding and salivary gland extracts induce volatile emissions in plants," Journal of Chemical Ecology, vol. 28, no. 9, pp. 1733-1747, 2002.

[68] T. C. J. Turlings, H. T. Alborn, J. H. Loughrin, and J. H. Tumlinson, "Volicitin, an elicitor of maize volatiles in oral secretion of spodoptera exigua: isolation and bioactivity," Journal of Chemical Ecology, vol. 26, no. 1, pp. 189-202, 2000.

[69] M. Hilker and T. Meiners, "Early herbivore alert: insect eggs induce plant defense," Journal of Chemical Ecology, vol. 32, no. 7, pp. 1379-1397, 2006.

[70] V. Velikova, G. Salerno, F. Frati et al., "Influence of feeding and oviposition by phytophagous pentatomids on photosynthesis 
of herbaceous plants," Journal of Chemical Ecology, vol. 36, no. 6, pp. 629-641, 2010.

[71] G. Salerno, E. Conti, E. Peri, S. Colazza, and F. Bin, "Kairomone involvement in the host specificity of the egg parasitoid Trissolcus basalis (Hymenoptera: Scelionidae)," European Journal of Entomology, vol. 103, no. 2, pp. 311-318, 2006.

[72] S. Colazza, G. Aquila, C. De Pasquale, E. Peri, and J. G. Millar, "The egg parasitoid Trissolcus basalis uses n-nonadecane, a cuticular hydrocarbon from its stink bug host Nezara viridula, to discriminate between female and male hosts," Journal of Chemical Ecology, vol. 33, no. 7, pp. 1405-1420, 2007.

[73] S. Colazza, M. Lo Bue, D. Lo Giudice, and E. Peri, "The response of Trissolcus basalis to footprint contact kairomones from Nezara viridula females is mediated by leaf epicuticular waxes," Naturwissenschaften, vol. 96, pp. 975-981, 2009.

[74] N. Mills, "Egg parasitoids in biological control and integrated pest management," in Egg parasitoids in agroecosystems with emphasis on Trichogramma, F. L. Cônsoli, J. R. P. Parra, and R. A. Zucchi, Eds., pp. 389-411, Springer, London, UK, 2010.

[75] B. S. Corrêa-Ferreira and F. Moscardi, "Biological control of soybean stink bugs by inoculative releases of Trissolcus basalis," Entomologia Experimentalis Et Applicata, vol. 79, no. 1, pp. 17, 1996.

[76] B. S. Corrêa-Ferreira, L. A. Domit, L. Morales, and R. C. Guimarães, "Integrated soybean pest management in micro river basins in brazil," Integrated Pest Management Reviews, vol. 5, no. 2, pp. 75-80, 2000.

[77] J. R. P. Parra, "Mass rearing of egg parasitoids for biological control programs," in Egg Parasitoids in Agroecosystems with Emphasis on Trichogramma, F. L. Cônsoli, J. R. P. Parra, and R. A. Zucchi, Eds., pp. 267-292, Springer, London, UK, 2010.

[78] F. L. Cônsoli and J. R. P. Parra, "In vitro rearing of parasitoids: constraints and perspectives," Trends in Entomology, vol. 2, pp. 19-32, 1999.

[79] F. L. Cônsoli and S. Grenier, "In vitro rearing of egg parasitoids," in Egg parasitoids in agroecosystems with emphasis on Trichogramma, F. L. Cônsoli, J. R. P. Parra, and R.A. Zucchi, Eds., pp. 293-313, Springer, London, UK, 2010.

[80] W. J. Lewis and W. R. Martin, "Semiochemicals for use with parasitoids: status and future," Journal of Chemical Ecology, vol. 16, no. 11, pp. 3067-3089, 1990.

[81] D. R. Papaj and L. E. M. Vet, "Odor learning and foraging success in the parasitoid, Leptopilina heterotoma," Journal of Chemical Ecology, vol. 16, no. 11, pp. 3137-3150, 1990.

[82] J. C. van Lenteren, "The state of commercial augmentative biological control: plenty of natural enemies, but a frustrating lack of uptake," Biocontrol, pp. 1-20, 2011.

[83] E. Wajnberg, J. K. Scott, and P. C. Quimby, Eds., Evaluating Indirect Ecological Effects of Biological Control, CABI Publishing, UK, 2001.

[84] J. C. van Lenteren, Ed., Quality Control and Production of Biological Control Agents. Theory and Testing Procedures, CABI Publishing, UK, 2003.

[85] C. C. Silva, M. C. B. Moraes, R. A. Laumann, and M. Borges, "Sensory response of the egg parasitoid Telenomus podisi to stimuli from the bug Euschistus heros," Pesquisa Agropecuaria Brasileira, vol. 41, no. 7, pp. 1093-1098, 2006.

[86] C. H. Krupke and J. F. Brunner, "Parasitoids of the consperse stink bug (Hemiptera: Pentatomidae) in north central washington and attractiveness of a host-produced pheromone component," Journal of Entomological Science, vol. 38, no. 1, pp. 84-92, 2003.
[87] D. B. Orr, J. S. Russin, and D. J. Boethel, "Reproductive biology and behavior of Telenomus calvus (Hymenoptera: Scelionidae), a phoretic egg parasitoid of Podisus maculiventris (Hemiptera: Pentatomidae)," Canadian Entomologist, vol. 118, pp. 1063-1072, 1986.

[88] F. M. Sales, J. H. Tumlinson, J. R. McLaughlin, and R. Sailer, "Behaviour of the parasitoid Trissolcus basalis (Wollaston) in response to kairomones produced by the host, Nezara viridula (L.)," Fitossanidade, vol. 2, pp. 80-83, 1978.

[89] F. M. Sales, "Normal reactions of females of the parasite Trissolcus basalis (Wollaston) (Hym.: Scelionidae) to the kairomonal extract of the eggs of the host, Nezara viridula (L.) (Hem.: Pentatomidae)," Fitossanidade, vol. 6-9, pp. 109-110, 1985.

[90] V. V. Buleza and A. V. Mikheev, "Localisation in the host's body of substances stimulating host-seeking by the egg parasite Trissolcus grandis (Thom.)," Khemoretseptsiya Nasekomykh, vol. 4, pp. 95-100, 1979.

[91] V. V. Buleza, "Mechanisms of search and choice of host in egg parasites (Hymenoptera, Scelionidae)," Zoologicheskii Zhurnal, vol. 64, pp. 1309-1317, 1985.

[92] S. Colazza and F. Bin, "Risposta di Trissolcus simoni (Mayr) (Hym.: Scelionidae) ad Eurydema ventrale Klt. (Het.: Pentatomidae) in olfattometro," in Proceedings of the Atti XV Congresso Nazionale Italiano di Entomologia, pp. 833-840, L’Aquila, Italy, 1988. 

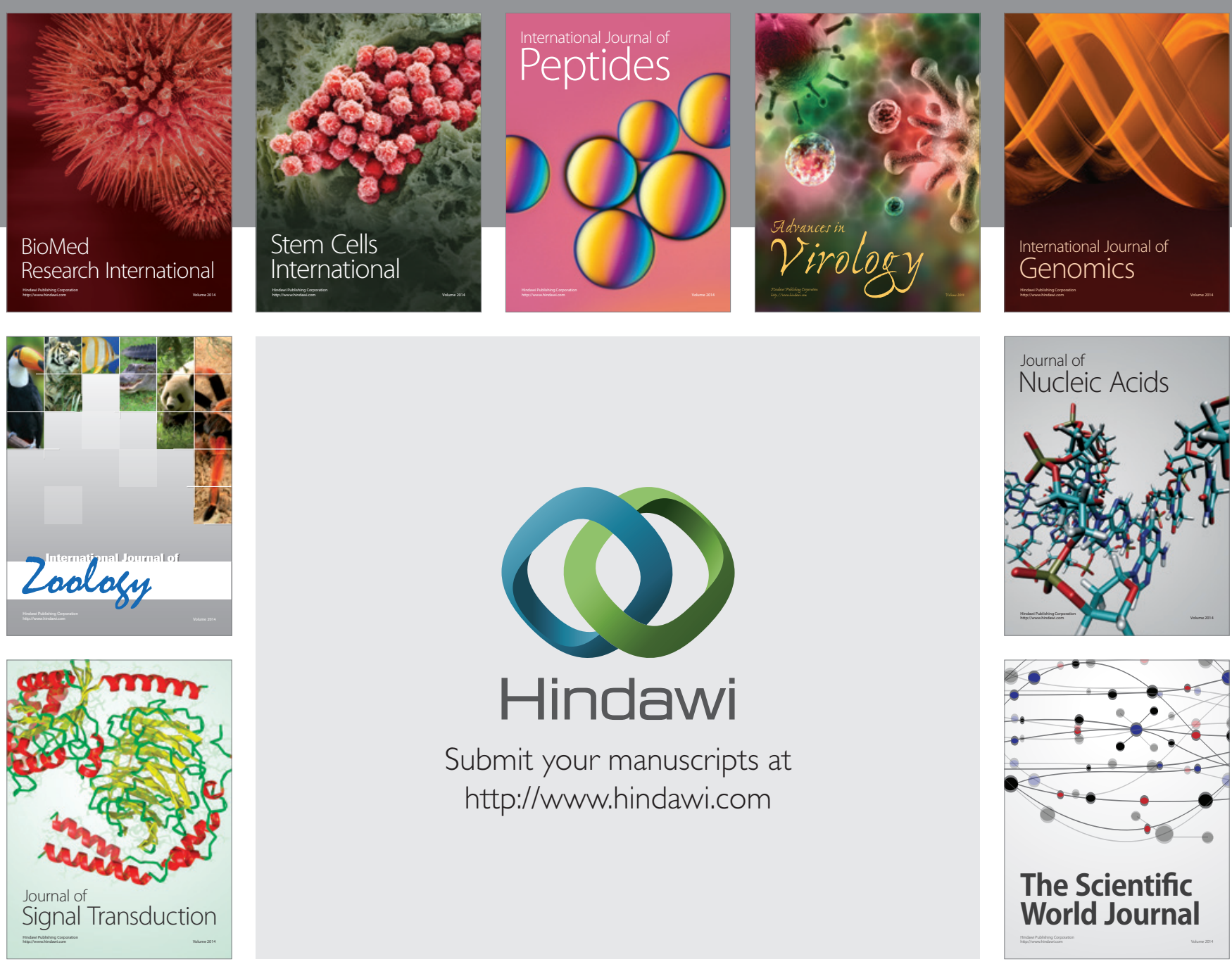

Submit your manuscripts at

http://www.hindawi.com
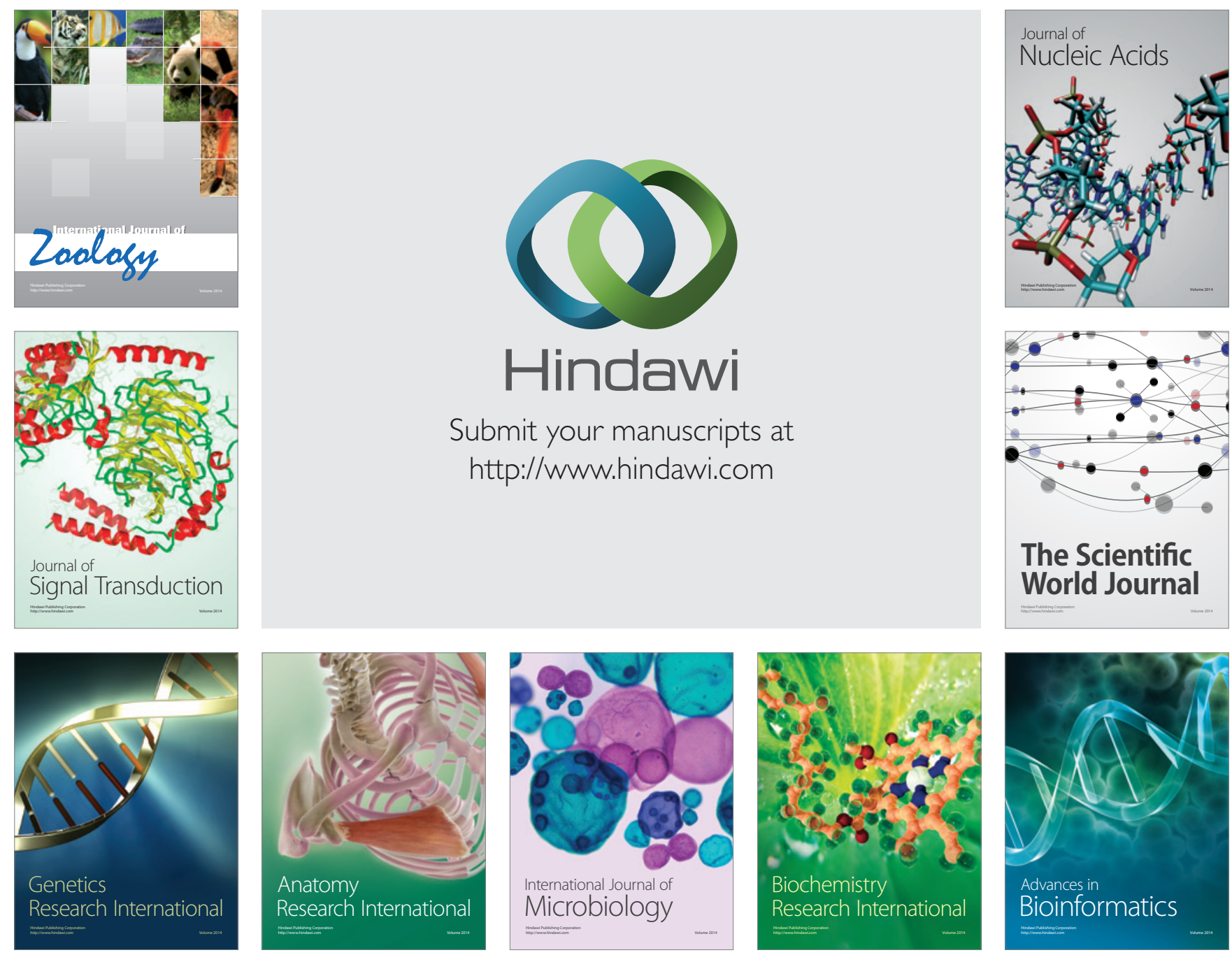

The Scientific World Journal
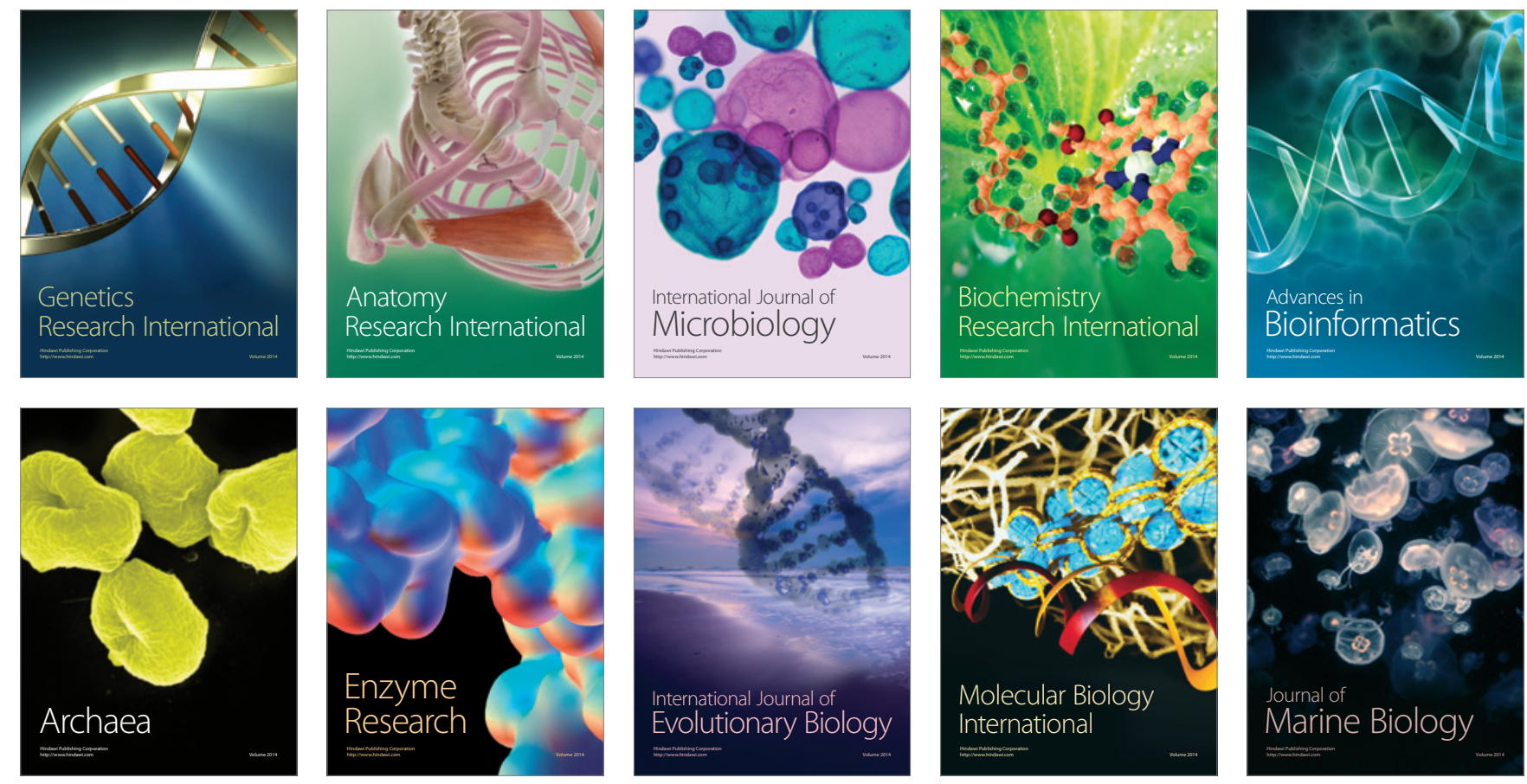